\title{
SOCIALNOGEOGRAFSKA REGIONALIZACIJA IN UPRAVNA REFORMA V REPUBLIKI SLOVENIJI
}

\author{
Igor Vrišer *
}

\section{IZVLEČEK}

UDK 911.63.001.7(497.12)

V razpravi so prikazani cilji bodoðe upravno-politið̌ne reforme $\mathbf{v}$ Republiki Sloveniji. $Z$ njo naj bi uvedli manjß̌e in samoupravno zasnovane obðine. Podane so tudi primerjave dosedanjih upravno-politicnih razdelitev Slovenije $\mathrm{z}$ omrežjem centralnih naselij in izhodišč za oblikovanje novih občin. Avtor obravnava tudi dileme o uvedbi morebitnih okrajev ali regij kot upravno-politǐnih enot srednje stopnje ter probleme, kako razdeliti heterogeno slovensko ozemlje $v$ tem smislu. Prekmurje kot nerazvito obmejno obmoxje v Sloveniji

\section{ABSTRACT}

UDC 911.63.001.7(497.12)

SOCIOGEOGRAPHIC REGIONALIZATION AND REFORM OF TERRITORIAL
ADMINISTRATION IN THE REPUBLIC OF SLOVENIA

The paper presents the aims of the future administrative-political reform in the Republic of Slovenia. It should introduce smaller and autonomous communes. Comparison between the present administrative-political regionalization of Slovenia and the network of central settlements is also presented, as well as the starting-points for the organization of new communes. The author also discusses the dilemma about the possible introduction of districts or regions as administrative-political units of medium rank, and also the problems of how to regionalize the heterogeneous Slovene territory to fit the above mentioned ideas.

I.

Vrnitev h kapitalističnemu družbenemu redu, demokraciji in večstrankarstvu je že skraja zastavila vpraŠanje, zlasti pa ob snovanju nove ustave in spremljajoxih zakonov, kako preurediti upravno-politično zgradbo Republike Slovenije, da bo ustrezala novim zahtevam in pravnim zasnovam. V ospredju sta bila dva problema, o katerih želimo podrobneje spregovoriti v tem porocilu, in sicer:

1. Kakšna naj bo nova obcina, kako velika naj bi bila ter kakšne funkcije naj ji pripadejo?

2. Ali naj bo upravno-politicna hierarhija dvostopenjska kot doslej, ali pa naj postane tristopenjska, kar bi pomenilo, da poleg občine in republike uvedemo $\mathrm{v}$ upravo se vmesno stopnjo okrajev, pokrajin ali regij, ter kakšne dejavnosti naj prepustimo tej hierarhicni ravni: samo-

\footnotetext{
* Dr, red. univ. prof, Oddelek za geografijo, Filozofska fakulteta, Aškerčeva 12, 61000 Ljubljana, Slovenija
} 
upravne ali prenašanje in izvajanje državnih funkcij?

Zastavljena vprǎ̌anja v marsiðem zadevajo tudi družbeno geografijo, Se posebej, ‘e upoštevamo, da ima upravno-politiðna ureditev in razdelitev očitne pokrajinske posledice, tako $v$ gospodarsko-kot $\mathrm{v}$ politično-geografskih pojavih in procesih ${ }^{\mathbf{1}}$. Razen tega je vsaka administrativna delitev tudi izrazit primer družbenogeografske regionalizacije, ki ima dolocene korenine razen $\mathrm{v}$ gospodarskih $\ \mathrm{e} \mathrm{v}$ populacijskih, socialnih in naselbinskih ter, ne nazadnje, $\mathrm{v}$ naravnogeografskih razmerah. Gre potemtakem tudi za eklatanten geografski problem, ki mu geografi moramó posvetiti ustrezno pozornost in, ce je le mogoce, tudi aktivno sodelovati pri njegovem vsebinskem obravnavanju in ozemeljskem razresevanju. $\mathrm{V}$ tem smislu naj bi bil zasnovan se tretji aspekt tega poroxila.

II.

Obxina kot upravna oblika je nastala na našem ozemlju po marčni revoluciji v letih 1849-50, ko so v Avstriji odpravili fevdalni red in so namesto patrimonialnih gospostev vpeljali obcino "kot temelj svobodne države" . Nove občine so oblikovali iz starih vaških sosesk (srenj) in žup in je njihovo ozemlje praviloma obsegalo eno ali (le izjemoma) ve` katastrskih obCin, v praksi pa vas in bližnje zaselke ${ }^{2}$. Občinam je država prepustila določeno pravno, upravno in financno samoupravo. Za to obliko obcinske samouprave bi lahko uporabili izraz "krajevna obcinska skupnost" (Ortsgemeinschaft), saj je v vecini primerov zajemala le lokalno skupnost. Zaradi tega so bile obcine praviloma majhne in so stele le nekaj sto prebivalcev. Na ozemlju R Slovenije jih je bilo $1269^{3}$. Vendar je bilo med njimi tudi nekaj mest, ki so imela poseben položaj (npr.Ljubljana, Maribor, Celje, Ptuj itd.) in so bila znatno vecja.

Že med obema svetovnima vojnama so se začele oblasti ukvarjati z reformo občin, predvsem $\mathbf{v}$ smislu njihovega združevanja in večanja. Družbeni razvoj, napredek v prometu, krepitev samouprave $\mathrm{v}$ občinah, prenašanje novih nalog nanje in krepitev komunalnih in drugih oskrbnih funkcij so terjali večje in populacijsko moxnejše obcine. Oblasti so to skusale doseci z združevanjem ali "komasacijo občin". Že takrat so postavile kot spodnjo velikostno mejo 3000 prebivalcev. ${ }^{4}$ Tudi v Slovenskem Primorju so italijanske oblasti izvedle podobno upravno zložbo $1.1936 .^{5}$

Po opustitvi krajevnih ljudskih odborov, ki so nastali kot rezultat revolucije med leti 1945-1952 in so $\mathrm{v}$ marsicem spominjali po svoji majhnosti in slabi opremljenosti na kasnejše krajevne skupnosti, so $1.1952^{6}$ oblasti vpeljale znova občine, vendar ne za dolgo. Že 1.1955 so jih začele združevati, 1. 1958 pa so vpeljale komunalni sistem in $\mathrm{z}$ njim vred tudi sedanje velike občne ${ }^{6}$. Po nekaterih nihanjih se je pojavila delitev na 62-65 obcin, pri cemer je bila ves cas problematǐ̌na členitev mest na občine (npr. Maribor). Kmalu se je pokazalo, da so nove obxine sicer gospodarsko ustrezale socialistiænemu sistemu, vendar pa so mocno zastrle lokalne interese in pobude. Zaradi te pomanjkljivosti, ki se je najbolj obcutila v premajhnem upoštevanju social- 
nih in prostorskih problemov in v nizki stopnji demokratičnosti,so zaceli v sedemdesetih letih vpeljevati krajevne skupnost kot nekakšn korektor pretirane centralizacije in zbirokratiziranosti. ${ }^{7}$ Krajevne skupnosti so se postopoma uveljavile zlasti na podeželju in so marsikje spominjale na stare predvojne obxine. $V$ mestih, kjer so bile vexidel oktroirane, so se manj obnesle in ljudje niso $\mathbf{v}$ njih videli tistih lokalnih skupnosti, ki izražajo in varujejo njihove interese, kot je to bilo na podeželju. Krajevnim skupnostim se je vezidel prepustilo urejanje lokalnih zadev, kot so razlieni socialni in komunalni problemi. Ker se jim je priznaval samo "samoupravni" status, so bile dokaj nestabilne in njihovo število je moxno nihalo: (1. 1971 jih je bilo 981, 1. 19811017 in 1. 1990 1214).

III.

Geografsko ovrednotenje vsakokratne upravne razdelitve obicajno opremo na spoznanja teorije o centralnih naseljih. Tako lahko ugotovimo, da so se obcine in njihova središa do 1 . $1958 \mathrm{v}$ glavnem uvrš̌̌ali $\mathrm{v}$ najnižje hierarhične stopnje in le v primerih mest, so sodila na višjo raven. Prve raziskave centralnih naselij (Kokole V. $1971^{8}$, Vrišer I. $1973^{\circ}$ ) so žal te najnižje stopnje centralnih naselij pušcale ob strani kot manj zanimive. Šele zadnja razprava s to tematiko (Vrišr, I. $1988^{10}$ ) je podrobneje zajela tudi te lokalne centre. Iz nje lahko povzamemo, da je bilo na ozemlju Republike Slovenije:

1. krajevnih (lokalnih) središ 392

2. podeželskih (ruralnih ali vicinalnih)središ 159

3. mikroregionalnih (obđinskih ali komunalnih središc) 57

in središ̌ višjih stopenj

Hierarhična opredelitev je bila izvedena na podlagi centralnih funkcij.Za uvrstitev med lokalne centre je takšno krajevno središce moralo biti sedež krajevne skupnosti, moralo je imeti trgovino in gostišca ter nepopolno osnovno solo. Za uvrstitev med ruralne in industrijske centre (vicinalna središa) pa naj bi imelo se ambulanto, pošto, popolno osnovno solo, trgovino $s$ kmetijskimi potrebšinami in bencinski servis. Na mikroregionalni ravni so centri morali posedovati poleg naštetega še specializirane trgovine, postajo ljudske milice, baň̌no poslovalnico, nekatere obrtne delavnice, kino in zdravstveni dom.

Iz primerjave je treba izvzeti mestne krajevne skupnosti, ki jih je bilo ca 226 , ker niso imele enakega pomena kot tiste na podeželju. Prav tako ni bilo mogoðe upoštevati obð̌in v mestih, ki so delila enotni mestni organizem. Tako reducirano stevilo krajevnih skupnosti bi znasalo ca 719 in bi za ca 110 primerov preseglo skupno క̌tevilo vseh središc. Ali drugađe povedano: ca 110 krajevnih skupnosti ni imelo najbolj osnovnih oskrbnih funkcij in bi jim glede na to praviloma ne mogli priznati upravnega pomena. Ugotovitev se mi zdi pomembna, ker so se ob predvideni upravni reformi pojavljala mnenja, da bi sedanje krajevne skupnosti enostavno proglasili za nove obxine. 
Nekoliko drugačen odnos nam da primerjava med centralnimi naselji in predvojnimi "komasiranimi" in povojnimi občinami iz l. 1952. Prvih (skupaj z onimi v Julijski krajini) je bilo 407, drugih pa 371. Vexina teh obcin je bila večja in bolje opremljena in so glede na to sodila na drugo hierarhično stopnjo. Takih središc smo v citirani raziskavi ugotovili 216 . To bi pomenilo, da so občinsko funkcijo dodelili tudi nekaterim manjsim središem I. hierarhǐ̌ne stopnje; ocitno so bili ponekod lokalni interesi močnejši, kot pa postavljena merila o občinski reformi.

Tudi na mikro-, mezo- in makroregionalni ravni so bile razlike obcutne. Razprava o centralnih naseljih v SR Sloveniji 1.1987 navaja 57 mikroregionalnih središx, število občin pa je nihalo med 62 in 65 . V avstroogrskem obdobju je bilo na sedanjem ozemlju R Slovenije 28 okrajev (in pet dežel). Med obema svetovnima vojnama so po ob̌̌inski reformi osnovali 25 okrajev (posebej so imela 4 mesta položaj okraja) in na italijanskem ozemlju 4 province, skupaj 29. Študija o centralnih naseljih navaja le 17 središ̌ mezo- in makroregionalnega značaja. Očitno je, da je upravna razdelitev le deloma sovpadala s hierarhijo centralnih naselij in da je državna uprava zasledovala pri delitvi različne politične cilje in se je le deloma ozirala na gravitacijo $\mathrm{k}$ središcem. V dokaz so nekateri močno vprašljivi okraji, kot npr. Logaški, Konjiski, Laški, Litijski ali npr. Koperšcina v Puljski provinci. Čeprav so slovenski geografi že v preteklosti iskali povezave med hierarhijo centralnih naselij, kot še vedno najboljš razlago o družbenogeografski Clenitvi pokrajine, in upravno politično ureditvijo (Melik, A. ${ }^{11}$, je treba vendarle ugotoviti, da sta se obe zasnovi le deloma skladali. Državna uprava je marsikje z umetnimi posegi pospeševala ali zavirala razvoj določenih središc ali spreminjala njihove funkcije. Upoštevati kaže, da so bili v vsem tem obdobju okraji, province in dežele praviloma instrument državne uprave, samouprave (razen na obxinski ravni) je bilo večidel malo. Pojavljati se je začela šele v zadnjih desetlet jih.

\section{IV.}

Kakšne so glede na povedano možnosti za oblikovanje nove upravne razdelitve? Prva izhodišca za snovanje novih občin nam daje že delovno gradivo za pripravo osnutka zakona o obcinah_ ${ }^{12}$. Po njem bodo nove občine:

1. samoupravne lokalne skupnosti, ki obsegajo eno ali več naselij in ki jih družijo skupne potrebe in interesi prebivalcev (clen I/5).

Obcina je obenem samostojna gospodarska enota, ki ima pravico gospodariti z vsemi vrstami premoženja (I/5). Osnuje se z zakonom, vendar po predhodno izvedenem referendumu (I/6). Po potrebi se lahko razdeli na vaške, krajevne ali druge skupnosti, mestne občine pa na cetrti (I/7).

2. Občina naj bo naravna in gospodarsko-družbena enota, ki je sposobna izpolnjevati z zakonom določene obveznosti (II/3). Zato naj ima občina najmanj 3000 prebivalcev in le izjemo- 
ma, zaradi prostorskih ali gospodarsko- družbenih razlogov, sme imeti manj kot 3000 prebival$\operatorname{cev}(\mathrm{II} / 3)$.

3. V obcini morajo biti prebivalcem zagotovljeni osnovni pogoji za življenje, ki obsegajo:

- trgovino z osnovnimi življenjskimi potrebšcinami,

- osnovno zdravnisko (in socialno) oskrbo,

- osnovno solanje,

- splošne komunalne in stanovanjsko-prostorske pogoje za bivanje,

- osnovne prometne in komunikacijsko-informacijske povezave (pošta),

- prostore za izvajanje upravnih in politienih dejavnosti (obcinska stavba)(II/4).

4. Čeprav je omejitev občinsłega območja odvisna od mnenja prebivalcev, vendar mora potekati tako, da ne seka katastrskih obcin (II/5). Do sprememb obxinskih meja lahko pride le, ce vsaka od prizadetih obcin po spremembi obmoxja lahko opravlja z zakonom dolocene naloge in ce to potrdijo prebivalci na referendumu.

5. Status mestne obxine lahko dobi obcina, ki ima najmanj 30000 prebivalcev in je geografsko, gospodarsko in kulturno središe in ðe to željo izrazijo prebivalci (IV/2).

Upoštevajoc ta dolocila bo bodoča slovenska občina socialno in gospodarsko samoupravno obmoxje. Bo razmeroma velika, saj bi praviloma morala šteti ve` kot 3000 prebivalcev, in bi morala izpolnjevati కest temeljnih funkcij. Oxitno so se tvorci zakonskega osnutka zgledovali po podobnih občinskih zakonih $\mathrm{v}$ tujini in po evropski listini o lokalni samoupravi, ki terja socialno in gospodarsko dobro opremljeno in trdno ter samoupravno naravnano občino. Razlike napram inozemskim občinam so predvsem glede velikosti. Težnja po večanju občinskega obmoxja je povsod prisotna, le da $\mathbf{v}$ gosto obljudenih predelih Nemcije in Italije terjajo minimalno Stevilo prebivalstva $4000-5000$ oziroma 10000 , na redkeje obljudenem Koroßkem pa vsaj 1500 prebivalcev. ${ }^{13}$ Sodobni družbeni razvojni trendi navajajo $\mathbf{k}$ večjim občinam in vsepovsod skuگajo odpraviti "pritlikave obcine", ki so se oblikovale v preteklem stoletju. Razlogi so znani: gospodarska samostojnost obxin, nujnost preseganja rentabilnega praga pri oskrbnih dejavnostih, večja dostopnost s prometnimi izboljšavami, manjऊ̌ navezanost občanov na obxinske urade zaradi gospodarske liberalizacije itd. ${ }^{14}$

Določila o novi občini nas močno spominjajo na izsledke teorije o centralnih naseljih. Tako bi lahko brez večjih pcmislekov uvrstili nove obcine glede na nujno opremljenost s storitvenimi dejavnostmi na II. hierarhično stopnjo, to je na raven ruralnih in podeželskih (vicinalnih) središc. Če se bomo teh vodil držali tudi v praksi, novih občin ne bo težko očrtati. Do težav bo prihajalo le $\mathrm{v}$ treh primerih. $\mathrm{V}$ nekaterih posebnih okolišinah bodo občine bržkone tudi manjse od 3000 prebivalcev. Na drugi strani bodo nastale mestne občine, ki bodo stele vec deset tisođ ali celo sto tisox prebivalcev, kar bo zelo velik razpon. Težave bodo zlasti v obmestjih, kjer bo zelo težko očrtati gravitacijska obmoxja manjših središx zaradi bližine mesta, mox̌ne urbanizacije in industrializacije. 
Kot dodatna vprasanja se bodo pri formiranju novih obcin zastavile se naslednje dileme. Kaj uporabiti kot osnovni gradbeni element: naselja, katastrske obcine, popisne oziroma stevne okolise ali nekatere agregatne teritorialne enote, kot so matixni okolisi, krajevni uradi in krajevne skupnosti? Kako ovrednotiti centralne funkcije $\mathbf{v}$ morebitnih bodocih obxinskih središcih, ali zgolj s prisotnostjo teh funkcij ali tudi glede na njihovo rentabilnost in frekvenco obiskovanja? Kako oxrtati njihova vplivna obmoxja? V kolikšni meri upoštevati nekdanjo upravno razdelitev: kot ふe vedno pomembno, kot priporoð̌ilo ali le kot opozorilo? Ena od kljuðnih dilem bo tudi: ali težiti $\mathbf{k}$ oblikovanju malih obðin, blizu velikostne meje 3000 prebivalcev ali raje snovati vecje obcine, vendar se vedno manjše od sedanjih. $V$ ne tako redkih primerih bo treba upoštevati posebne naravne in \e pogosteje družbene razmere, kot so npr. prisotnost narodnostne manjßine, homogena socialna zgradba, primerna prometna povezanost itd. Oxitno je, da oxrtavanje novih obđ̌in ne bo moglo potekati na mehanicen naxin, ampak da bo treba upoštevati mikroregionalne razmere, $v$ nasprotnem se zna zgoditi, da bodo prebivalci na kasnejšem referendumu zavrnili ureditev. Lahko re`emo, da gre za vrsto ne le politicnih ali socialnih dilem, ampak za izrazito geografsko problematiko.

Ob prvih poskusih clenitve R Slovenije na nove obðine v smislu zgoraj postavljenih izhodiš se je pokazalo, da lahko racunamo $\mathrm{z}$ okoli 245-270 obcinami ${ }^{15}$.

Iz povedanega je razvidno, da so temeljna vprašanja o bodoci obxinski ureditvi bolj ali manj razciš̌ena. Preostaja Se izvedba razdelitve, ki bo bržkone vzbudila veliko zanimanja, pa tudi pomislekov in ugovorov med obðani.Tega ne kaže podcenjevati, saj jo bo $\mathbf{v}$ prihodnje mogoč spreminjati,potem ko bo potrjena, le izjemoma in pod težkimi pogoji.

V.

V dosedanjih razpravah o upravnopolitični ureditvi R Slovenije je vprašanje Sirsih lokalnih skupnosti, to je okrajev, pokrajin ali regij, ostalo odprto. Na ustavni komisiji niso dosegli soglasja o tem, ali so te skupnosti sploh potrebne in, ‘e so, kakŠno vlogo naj bi imele. V razpravi sta ves cas prisotna dva koncepta: 1) da so transmisija državne uprave in 2) da so samoupravne skupnosti obঝin. Resnici na ljubo je treba povedati, da je v veðini držav v Evropi ta stopnja urejena kot izpostava državnih oblasti pri reševanju določenih nalog (davěna služba, inšpektorat). V novejšem Casu pa se vloga okrajev postopoma spreminja. Čedalje bolj dobivajo samoupravni znacaj. Razlogi so $\mathbf{v}$ narašcanju regionalnih problemov, ki jih obðine niso sposobne reševati zaradi svoje majhnosti (prostorsko urejanje, vodna oskrba, cestno omrežje, deponije odpadkov, rekreacijske površine, solsko in zdravstveno omrežje). Prav tako narašcajo tudi zahteve po upoštevanju specificnih regionalnih interesov in posebnosti, ki jih ni mogoðe reševati na uniformiran nađin iz centra. Zato $\mathrm{v}$ mnogih državah dobiva ta srednja hierarhǐ̌na stopnja cedalje bolj samoupravni znacaj. Seveda to ne pomeni, da se države spreminjajo v " regionalne federacije", ceprav se slišjo tudi takšne pobude. Sodimo, da bi pri razmisljanjih o bodoci upravno-politǐ̌ni ureditvi Slovenije morali poiskati vmesno rešitev, ki bi upoštevala, da so: 
1. zaradi majhnosti občin, regionalnih specificnosti, regionalnih problemov in boljš transmisije upravljanja regionalne upravne enote potrebne;

2. enote naj bi imele dvojni znacaj: naj bi bile glede določenih funkcij izpostave oblasti, glede drugih nalog pa bi urejale samoupravne interese prizadetih obcin; ${ }^{16}$

3. regionalizacija nudi tudi dolocena jamstva, da se republika ne bo razvijala centralistixno, ampak policentrixno, kar je glede na velike razvojne razlike med slovenskimi pokrajinami nujno in vsestransko spre jeto stališce.

Nic manj ni razrešeno tudi nadaljevanje zgoraj navedenih dilem, namrex, kako zamisljeno regionalizacijo, ce bo sprejeta, izpeljati in zadostiti enim in drugim zahtevam. V zelo heterogeni Sloveniji to ni preprosta naloga. Ali se npr. odloxiti za dvostopenjsko hierarhijo (okrožje-okraj ali pokrajina-okraj) ali za enotno srednjo hierarhično stopnjo med občnami in republiko. V ilustracijo: ali pokrajino Severovzhodno Slovenijo obravnavati enotno ali jo deliti na tri enote: Korosko, Podravsko in Pomursko regijo, ali jih celo razlikovati po pomenu: pomembnejša Mariborska in manj pomembna (Koroska regija).

$\mathbf{Z}$ uporabo ene ali druge regionalizacijske metode pridemo do zelo razlixnih rezultatov. S podrobno clenitvijo razpade Slovenija na okoli 25-29 enot. Avtor tega prispevka se zavzema za clenitev na 12 regij $^{17}$, ki so se izoblikovale že $v$ dosedanjem upravljanju in so nastale na samoupraven način. Možna bi bila delitev tudi na 8 regij, s tem da nekatere manjふ̌se podredimo večjim enotam (npr. inkorporacija Zasavja v Osrednjeslovensko regijo). Delitev na 3-4 enote po našem mnenju ne pride $\mathrm{v}$ poštev, saj bi s tem docela zabrisali njihove regionalne specificnosti, a to je razlog, da se zanje sploh zavzemamo.

\section{LITERATURA IN VIRI}

1. Hagel, J., 1984: Politische Geographie, Sozial-und Wirtschaftsgeographie, 3,Harens Handbuch der Geographie, Muenchen, str.293

2. Vilfan S., 1961: Pravna zgodovina Slovencev, Ljubljana, str. 448-453

3. Jambrek P.,Kos J.,1979: Razvoj lokalne samouprave v Ljubljani, 1941-,979, Preoblikovanje krajevnih skupnosti v Ljubljani, str.18-21. Avtor tega poroxila je naštel 1229 občin.

4. Trstenjak, D;1939: Uprava v Sloveniji, Spominski zbornik Slovenije, Ljubljana, str.124

5. Čermelj, L.;1965: Slovenci in Hrvati pod Italijo med obema vojnama, Ljubljana, str. 38-46

6. Cerovac, P.,1964: Upravno-teritorialno oblikovanje SR Slovenije , upravno-teritorialnimi enotami 1945-1964, Prikazi in Studije, X/7-6, str.1-59

7. Vlaj, $S ; 19,9$ : Ustavna koncepcija krajevne skupnosti in oblikovanje krajevnih skupnosti v Ljubljani, Preoblikovanje krajevnih skupnosti v Ljubljani, str.13-17

8. Kokole, V;1971: Centralni kraji v SR Sloveniji, Geografski zbornik, XII, str.5-112 
9. Vrišer, I.,1973: Vplivna območja slovenskih mest. Stanje v prostoru in razvojne težnje, dokumentacijsko gradivo II, RPP za obmocje SR Slovenije, str97-106

10. Vrißer, I;;1988: Centralna naselja v SR Sloveniji leta 1987, Geografski zbornik, XXVII, str.131-151

11.Melik, A.,1952: Upravno-teritorialna razdelitev v luči geografsko-gospodarskih ciniteljev, Ljudska uprava, V, str. 251-256

12. Delovno gradivo za pripravo zakona o obæ̌inah, Skupšcina Republike Slovenije, 30.9.1991, Ljubljana

13. Koeffner, A, 1974: Urbanisierungstendenzen und Gemeindezusammenlegung in Oesterreich, Mitt.d.oesterr.geogr. Gesellschaft, 116, I-II, str.228-236

14. Glanzer, O.,Unkart R.,1973: Die Neuordnung der Gemeindestruktur in Kaernten in Jahre 1972, Raumordnung in Kaernten, Klagenfurt

15. Vrišer, I.,1991. Oblikovanje novih obð̌in v Republiki Sloveniji, skupšcina Republike Slovenije (razmnoženo poroxilo)

16. Vrišer, I.,1991: Oblikovanje novih občin v Republiki gradivo za pripravo zakona o občinah, Skupšcina Republike Slovenije, Ljubljana

17. Vrišr, I.,1991: Ekonomskogeografska regionalizacija Republike Slovenije, Geografski zbornik, XXX, Ljubljana, str. 129-240

\section{SOCIOGEOGRAPHIC REGIONALIZATION AND REFORM OF TERRITORIAL ADMINISTRATION IN THE REPUBLIC OF SLOVENIA}

Since the social order was abolished in Slovenia, and the capitalist system and democracy were reintroduced, a need has arisen to reorganize the administrative-political system of the Republic on the fundamental level of communes as well as larger districts or regions on medium level.

Communes were introduced on the territory of Slovenia in the years $1849-1850$, after feudalism had been abolished in Austria. They were very small-sized and had the character of local communities (a village with nearby hamlets). Already between the two World Wars the authorities tried to fuse these small communes into laerger ones, but without greater success. New reforms were carried out in the year 1952, when communes, following the pre-War pattern, were introduced for a shorter span of time, and again in the year 1958, when a "system of commune" with very large communes was introduced. It was fully adapted to socialist social order. These large communes proved to be very centralistic, so in the seventies the authorities intervened by introducing local communities; these were meant to provide greater respect of local interests. Nevertheless, local communities never had administrative power. They were useful and active in the rural areas, while in towns they were more or less bestowed on. 
In geographic analyses, administrative-political regionalization is mostly established by means of comparison with the network and hierarchy of central settlements. A comparison with the present central-settlement network in the Republic of Slovenia has shown that the administrative-political regionalization in the past only partially corresponded to this network and so does that of the present. On the whole, communes and districts substantially outnumbered corresponding centers, which proves that administrative authorities made several exceptions and assigned communal or district functions also to centers which did not comply with the required conditions. This can also be seen from the following Table:

Comparison of the central-settlement network with administrative political regionalization of the Republic of Slovenia

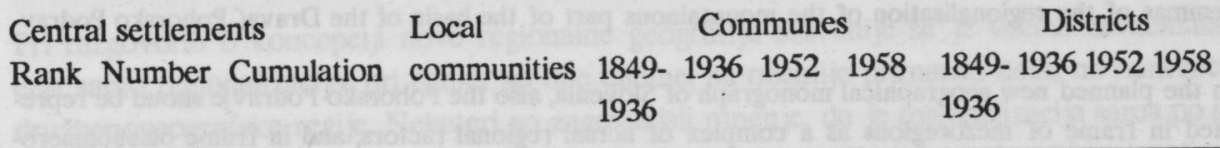

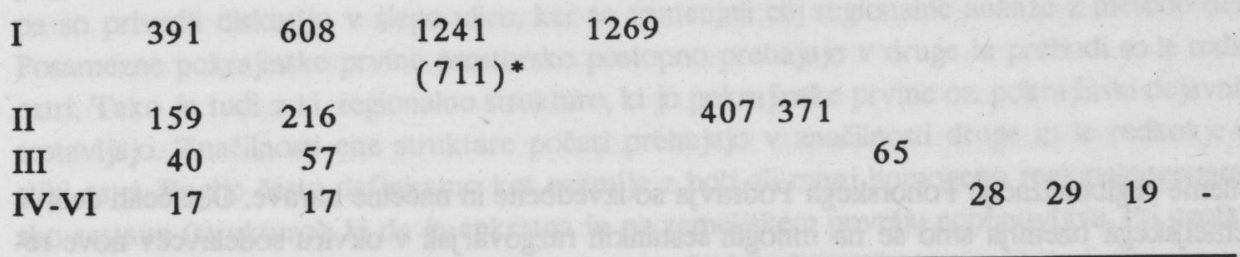

* without municipal local communities

Planning new kind of communes is based on the European Document on Local Autonomy and on the examples of the neighbouring countries. New communes should, as a rule, have more than 3000 inhabitants. As socially and economically autonomous and rounded off areas, they should also have the following fundamental services: a shop, an elementary school, a medical station, a post office, communal infrastructure and residential facilities and a building for the communal assembly. Introductory analyses performed by the author of this report show that 245-270 communes, fulfilling the above mentioned conditions, could be formed on the territory of the Republic. However, their number will be higher since several exceptions will have to be taken into account. As concernns the districts, it has not been decided yet, whether the authorities will introduce them or not and what their function will be: whether they will be the transmission of State administration, or they will have, as a group of communes, certain autonomous rights. Also the regionalization of the Slovene territory is remaining an open question. In detailed regionalization there would be appr. 25-29 districts or 8-12 provinces or regions, while in less detailed regionalization, there would only be 3-4 units. The author supports the idea of 12 provinces which have already been effective in the political and economic life so far. 